\title{
Awareness and Attitude to Social and Health Hazards from Portable Power Generator in Commercial Areas of Karachi, Pakistan
}

\author{
Durdana R Hashmi* and Akhtar Shareef \\ PCSIR Laboratories Complex, Pakistan
}

ISSN: 2637-8078

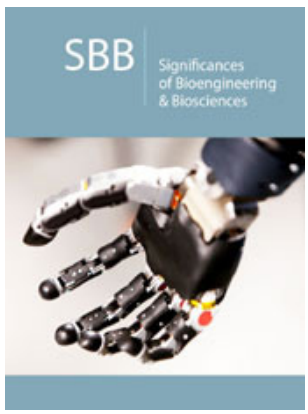

*Corresponding author: Durdana $\mathrm{R}$ Hashmi, PCSIR Laboratories Complex, Pakistan

Submission: 佂 November 13, 2019

Published: 比December 13, 2019

Volume 3 - Issue 5

How to cite this article: Durdana R Hash$\mathrm{mi}^{*}$ and Akhtar Shareef. Awareness and Attitude to Social and Health Hazards from Portable Power Generator in Commercial Areas of Karachi, Pakistan. Significances Bioeng Biosci.3(5). SBB.000574.2019. DOI: 10.31031/SBB.2019.03.000574

Copyright@ Altalhi KGH, This article is distributed under the terms of the Creative Commons Attribution 4.0 International License, which permits unrestricted use and redistribution provided that the original author and source are credited.

\begin{abstract}
The acute shortage of electricity in Pakistan has led to indiscriminate, unregulated and prolong use of generators for electricity by the citizens, contributing the noise pollution in the country. The aim of this study was to estimate the level of noise pollution and possible health impacts from the use of portable electricity generators at 04 locations areas selected in commercial of Karachi city. Impacts of noise pollution were calculated by a semi-structured questionnaire interview method regarding the health hazards associated with the noise of portable power generators. Survey was conducted with 310 persons, randomly selected as shopkeepers, office workers and push-carters. Results showed that continual exposure of generator noise producing adverse health effect on the habitants includes hearing loss, noisiness, sleep disturbances, cardiac disturbances, impaired task performance, annoyance and bad behavioral reactions. This negative health effect of noise pollution among residents of the city needs urgent attention.
\end{abstract}

Keywords: Health hazards; Environment; Exposure; Portable generator; Noise pollution

\section{Introduction}

World Health Organization ranked third position to noise pollution after water and air pollution. Noise pollution problem is becoming a universal issue in developing countries and an important factor for public health problems [1]. Presently in our country, one of the main causes of noise pollution is portable power generators. The Severe shortage of electricity in Karachi city has directed to indiscriminate, unregulated, and prolong use of portable electric power generators for electricity by her citizens. A portable power generator is a gasoline, petrol or diesel-powered device that is used as an alternative temporary arrangement of electrical power supply up to certain voltage [2]. Portable power generators are used very commonly in shops, offices and homes as an alternative source of power supply during power shutdowns period $[3,4]$. These generators emit very high levels of noise, in addition to noxious air pollutant emissions.

According to the recent researches noise is now considered as a serious health hazards in our modern societies [5]. Prevalence of both auditory and non-auditory effects is widespread among the workers/operators working in a noisy environment. The non-auditory hazards of noise include irritation, anger, loss of memory and sleeping disorders [6]. World Health Organization (WHO) estimated that 360 million peoples in the world disabling the hearing loss, out of which $91 \%$ are adults and only $9 \%$ are children [7]. Incidence of disabling hearing impairment in South East Asia is $2.4 \%$ in children, 9.5\% in adults below 65 years and up to $48 \%$ in adults above the age of 65 [8].

\section{Materials and Methods}

This study was conducted at 04 locations in commercial areas of Karachi. All the selected locations were highly commercial activities areas surrounded by different types of shops, offices, pushcarts and commercial cum residential buildings. A comparative cross-sectional study design was used which involved questionnaire to the participants/generator users. 
The questionnaire assessed a cross-section of different age groups, educational levels/literacy level and occupation of respondents. The general population who had participated in this study included small business shops keepers, office workers, loaders and push carters above 16 years of age in all the selected areas and categories. A semi-structured questionnaire was used to gain information on the perception and knowledge from the participants regarding the Health hazards of noise. The questionnaire was divided into three sections. First section asked some general questions, such as age, occupation and educational status. The following section incorporated the questions on the status of Knowledge/Information about hazardous effects and the last section of the questionnaire, asked the questions to examine the risk/hazards with the exposure of generator noise on human health.

\section{Results}

(Figure 1) presented the percentage of the respondents according to the age limit. It reveals that majority $267(86.1 \%)$ of the respondents were aged above 20 years. Of these a large number (54.5\%) belongs to 30-50 years age, while 43(14\%) were below 20 years of age group.

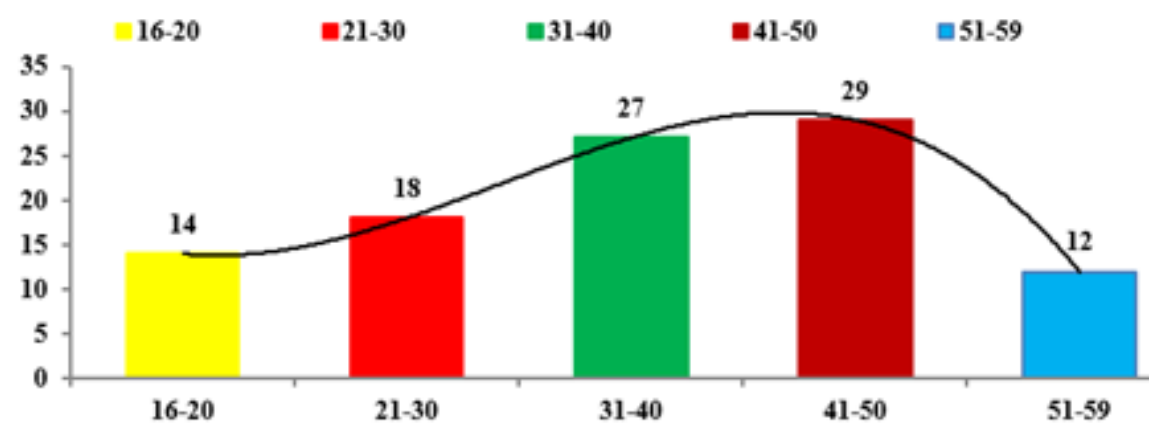

Figure 1: Respondents according to the age group

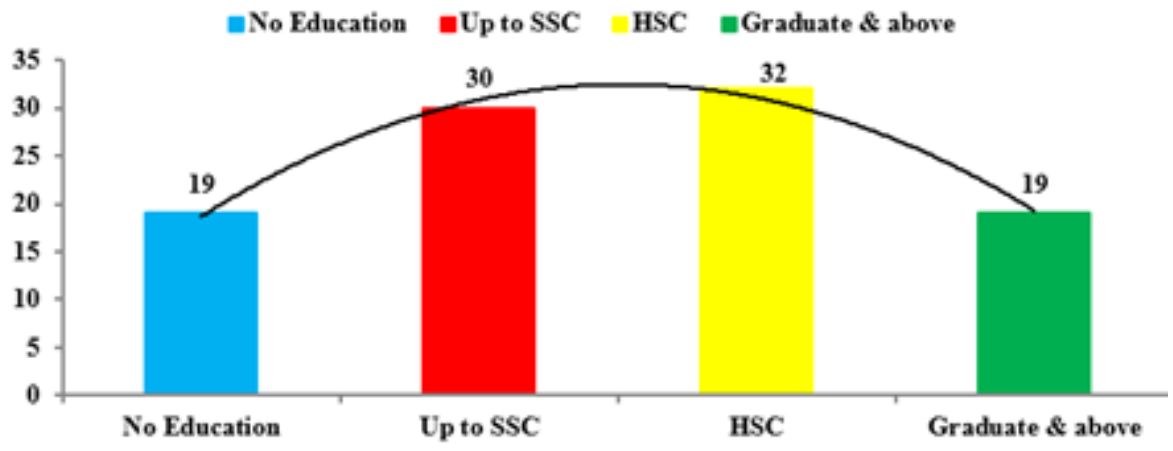

Figure 2: Level of education of the respondent.

(Figure 2) presented the percentage of the respondents according to the level of education, $19 \%$ of the respondents have no education, whereas $30 \%$ of the respondents were educated up to secondary school certificate (level 10) and from the remaining
$51 \%$ respondents, 32\% were educated up to higher secondary school certificate (level 12) and 19\% were having graduate and above level education.

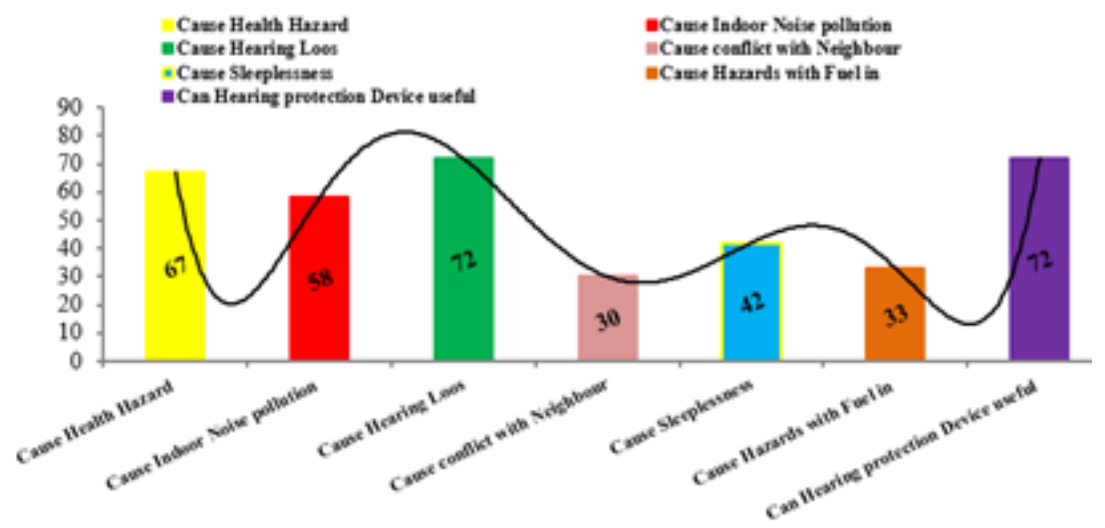

Figure 3: Percentage of respondents according to awareness/knowledge of health hazards. 
(Figure 3) presented the percentage of respondents according to the awareness/knowledge of Health Hazards associated with Portable Power Generators in home shops and workplace. More than half of the respondents 209(67.4\%) agreed that use of portable electric generators cause great harm on human health. 223(72\%) were well informed about the fact that noise can cause impaired hearing, a large percentage $180(58 \%)$ indicated that portable power generator is major source of indoor noise pollution. Less than half of the respondents $94(30 \%)$ believed that noise from the use of portable generator can bring about conflict among neighbors, $102(33 \%)$ assumed that dispensing fuel into the portable power generator could pose any danger to human and environment. Surprisingly less than $50 \%$ of the participants $132(42 \%)$ agreeing to the fact that exposure to noise from power generator can cause sleeplessness. Majority of the respondents 223(72\%) agreed that use of hearing protection device can protect oneself from hearing impairment.

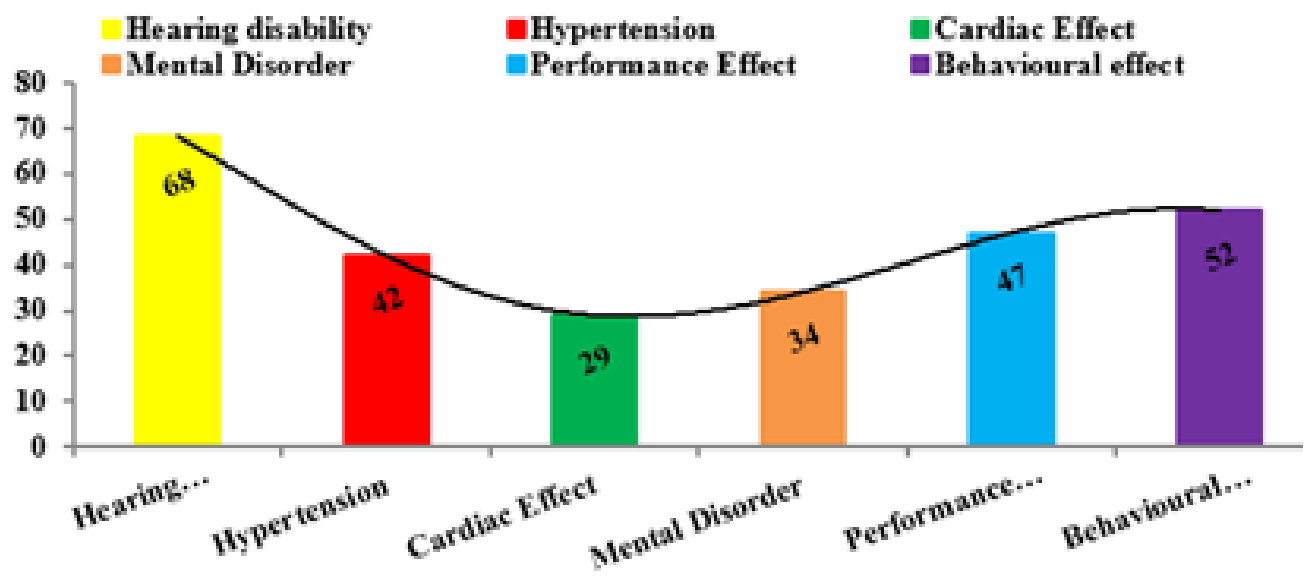

Figure 4: Percentage of respondents according to the risk of health.

(Figure 4) presented the percentage of respondents according to the awareness/knowledge about health risk with the use of Portable Power Generators. A large percentage of participants $212(68 \%)$ respond that by the indoor use of portable electric generators they feel hearing disability (specially in adults), whereas half of the respondents $162(52.3 \%)$ indicated that indoor use of portable generator shows behavioral effect specially in female as they spent most of the time in the indoor environment for housekeeping. Similarly, about half respondents $146(47 \%)$ also complain about performance effects due to noise intensity in the indoor and outdoor environment. Less than half of the respondents 132(42\%) believed that noise producing from portable generator in house, shops and at workplace causing hypertension problem. Similarly, very low percentage of the respondents 106(34\%) showing some mental disorder similarly 91(29\%) complained about cardiac effects due to regular use of power generator in the indoor environment during electricity shut down period.

\section{Discussion}

Present study was conducted at 04 locations in commercial areas of Karachi. A semi-structured questionnaire was used to gain information on the perception and knowledge from the participants regarding the hazardous effects associated with power generator noise. The age of Participants in this study from all the selected locations ranged from 16 to 59 years. Majority (82\%) were above 20 years while $(14 \%)$ were below 20 years of age (Figure1 \& 2). Knowledge and awareness about Health Hazards presented in
(Figure 3 \& 4) respectively. High level of Knowledge and awareness $(67 \%)$ was noticed among the users of portable power generators about health hazards (58\%) participants respond that presently one of the major sources of noise pollution is power generators, using 03 times daily for two hours during load shedding period. According to the recent researches on noise pollution hazards majority of the respondents agreed to the fact that noise pollution is a source of hearing impairment [9]. Result regarding the use of hearing protection devices such ear plug and earmuffs in order to protect from hearing loss is not surprising because some of them were already using cloths and scarf to protect their ears from noise pollution hazards.

The efficiency of hearing protection devices in preventing the noise induced hearing loss is mainly depend on the correct choice, use and properly wearing these protection devices [10]. Results of a study that was conducted in a steel rolling mill in Nigeria, shows that less than half of the workers were properly using Hearing Protection Devices (HPDs), due to the lack of awareness and information regarding the noise induced health hazards [11]. Sleep disturbance is one of the serious problems due to noise pollution. Result of this study regarding the sleep disturbance due to power generator noise is surprising, as less than half of the respondents were agreed that generators noise could cause sleep disturbance. One of the reasons might that due to hard working in day/nighttime the noise of generator is uncountable factor than the sleep, in the view of respondent noise is bearable than the hotness of summer season. 
According to the World Health Organization (WHO) guideline noise level for a good sleep is $30 \mathrm{~dB}(\mathrm{~A})$, while noise levels exceeding $45 \mathrm{~dB}(\mathrm{~A})$ should be avoided [12]. Regarding the question about conflict among neighbors, less than half of the respondents were agreed to this fact. According to the National Environment Quality Standards (NEQS), the limit for noise in residential areas was set at 55 decibels during the day and $45 \mathrm{~dB}$ during the night., Whereas, diesel generators generate $88 \mathrm{~dB}$ of noise, while generators running on petrol or gas can go above $95 \mathrm{~dB}$ (Published in The Express Tribune, May $22^{\text {nd }}, 2011$ ),

\section{Conclusion}

The present study shows that commercial areas of Karachi are highly exposed to noise pollution. Due to shortage of electricity and erratic shutdown of power supply, inhabitants are immense to use portable power generators in homes, offices and their workplace during shutdown period that are producing noise pollution and serious health hazard. Results show that most of the respondents had high level knowledge about the harmful effects of noise at workplace and home. Main finding of this study is that majority of the respondents revealed that noise induce hearing loose (NIHL) had low priority than other health hazards such as cancer, cardiovascular disease, pulmonary problems, chemical burn and other issues in the life.

There is a need of eco-city planning and of arranging awareness program on noise pollution hazards to train the workers about harmful effects of noise pollution on hearing disability, stating the level at which noise is considered dangerous. Necessary preventive measures must also be taken by the government and appropriate authority to implement the noise pollution (Regulation and Control) Rules.

\section{References}

1. Azodo AP, Adejuyigbe SB (2013) Examination of noise pollution from generators on the residents of Obantoko Ogun state, Nigeria. Asian J Eng Sci Technol 3(1): 31-41.

2. Ashmore MR, Dimitroulopoulou C (2009) Personal exposure of children to air pollution. Atmospheric Environment 43(1): 128-141.

3. Ibitoye FI, Adenikinju A (2007) Future demand for electricity in Nigeria. Applied Energy 84(5): 492-504.

4. Azodo AP (2014) Electric power supply, main source and backing: A survey of residential utilization features. Int J Res Stud Manage 3(2): 87102.

5. Stansfeld S, Haines M, Brown B (2000) Noise and health in the urban environment. Rev Environ Health 15(1-2): 43-82.

6. Evans GW, Lercher P, Meis M, Ising H, Kofler WW (2001) Community noise exposure and stress in children. J Acoust Soc Am 109(3): 10231027.

7. World Health Organization (2014) Deafness and hearing impairment fact sheet.

8. WHO (2012) Global estimates on prevalence of hearing loss?

9. Jibiri NN, Olaluwoye MO, Ayinmode BO (2015) Assessment of health effects of noise and vibration levels at major business complexes and markets in Ibadan metropolis, Nigeria. Journal of Health Science 5(4): 69-75.

10. Yesufu AL, Ana GREE (2012) Electric generator characteristics, pattern of use and non-auditory health effects experienced by commercial workers in Agbowo and Ajibode areas of Ibadan, Nigeria. Review of Global Medicine and Healthcare Research 3(2): 159-171.

11. Anya AA, Solomon NC, Paul CO, Aguh PS (2017) Effects of noise and vibration on subjects exposed to electrical power generating set pollution. Advances in Research 11(4): 1-11.

12. World Health Organization Regional Office for Europe (2004) Noise and sleep technical meeting on sleep and health. Bonn, Germany. 